\title{
As estruturas sociais e seus impactos no campo do ensino superior de música nas universidades federais do Brasil
}

\author{
Social structures and their impacts on the field of university education in music at federal \\ universities in the Brazil \\ Las estructuras sociales y sus impactos en el campo de la enseñanza superior en música en las \\ universidades federales de Brasil
}

\author{
Rodrigo Fernandes de Lucena \\ ORCID: https://orcid.org/0000-0003-0206-6700 \\ Universidade Federal do Ceará, Brasil \\ E-mail: rodrigofernaandes@ hotmail.com \\ Elvis de Azevedo Matos \\ ORCID: https://orcid.org/0000-0003-3522-0305 \\ Universidade Federal do Ceará, Brasil \\ E-mail: tioelvis@gmail.com \\ Leandro de Abreu Andrade \\ ORCID: https://orcid.org/0000-0002-0796-0464 \\ Universidade Federal do Ceará, Brasil \\ E-mail: leandrodeabreuandrade@gmail.com \\ Yure Pereira de Abreu \\ ORCID: https://orcid.org/0000-0002-2151-2502 \\ Universidade Federal do Ceará, Brasil \\ E-mail: yuredeabreu@alu.ufc.br
}

\begin{abstract}
Resumo
Trata-se de um artigo teórico de cunho sociológico-educacional que visa a analisar e debater os aspectos históricos e sociais que permeiam a utilização de testes de habilidade específica em cursos de nível superior em música de universidades federais brasileiras. A partir das perspectivas estruturalista e reprodutivista de Bourdieu (1996, 2007, 2009) e do conceito de habitus conservatorial de Pereira (2012), propomos um breve debate sobre as relações de dominação nas estruturas sociais e seus impactos no campo do ensino de nível superior de música em universidades federais. Concluímos, a partir das perspectivas de Bourdieu (1996, 2007, 2009), de Pereira (2012) e de ThiryCherques (2006), que os Testes de Habilidade Específica são utilizados como ferramentas reprodutoras de um sistema social dominante que limita, consciente ou inconscientemente, o acesso aos cursos de nível superior em música para as classes menos favorecidas. Observamos a necessidade de um debate mais aprofundado sobre este tema a fim de se criar um ambiente favorável à democratização do acesso ao conhecimento musical em meio ao ensino superior, através de uma educação gratuita e de qualidade nas universidades federais brasileira.
\end{abstract}

Palavras-chave: Habitus; Habitus conservatorial; Teste de habilidade específica; Ensino; Ensino de música.

\begin{abstract}
This is a theoretical article of a sociological and educational nature that aims to analyze and debate the historical and social aspects that permeate the use of Specific Skill Tests in Music Degree Courses at Brazilian federal universities. From the structuralist and reproductive perspectives of Bourdieu (1996, 2007, 2009) and Pereira's concept of conservatorial habitus (2012), we propose a brief debate on the relations of domination in social structures and their impacts in the field of higher education in federal universities. It was concluded, from the perspectives of Bourdieu (1996, 2007, 2009), Pereira (2012) and Thiry-Cherques (2006), that the Specific Skill Tests are used as reproductive tools of a dominant social system that restricts, consciously or unconsciously, access to undergraduate music courses for the least favored classes. There is a need for a more in-depth debate on this topic in order to create a favorable environment for the democratization of access to higher musical knowledge, through free and quality teaching at Brazilian universities.
\end{abstract}

Keywords: Habitus; Conservatory habitus; Specific skill Test; Education; Music education.

\section{Resumen}

Este es un artículo teórico con carácter sociológico-educativo que tiene como objetivo analizar y debatir los aspectos históricos y sociales relacionados al uso de pruebas de habilidad específica en cursos de nivel superior en música de 
las universidades federales brasileñas. A partir de los proposiciones teóricas estructuralista y reproductivo de Bourdieu (1996, 2007, 2009) y del concepto de Habitus del conservatorio de Pereira (2012), proponemos un breve debate sobre las relaciones de dominación en las estructuras sociales y sus impactos en el campo de la enseñanza superior en música en universidades federales. Conclusiones: a partir de las proposiciones de Bourdieu (1996, 2007, 2009), de Pereira (2012) y de Thiry-Cherques (2006), podemos concluir que las pruebas de habilidad específica son usadas como herramienta reproductiva del sistema social dominante que limita, consciente o inconscientemente, el acceso a los cursos superiores de música para las clases menos favorecidas. Observamos la necessidad de realizar un análisis más profundo sobre este tema con el fin de crear un entorno propicio para la democratización del acceso al conocimiento musical en medio de la enseñanza superior, mediante una educación gratuita y de calidad en las universidades federales de Brasil.

Palabras clave: Habitus; Habitus Conservatorial; Prueba de habilidad específica; Enseñanza; Enseñanza de la musica.

\section{Introdução}

O conceito de habitus, apresentado por Bourdieu (2009), representa a compreensão das individualidades de um sujeito, considerando as objetividades e as subjetividades presentes nas relações sociais que ocorrem entre os indivíduos de um mesmo contexto social. O cerne da sua conceituação busca explicar as ações, os esquemas comportamentais e os pensamentos dos sujeitos, bem como, suas origens, aspectos que determinam a maneira como o indivíduo se comportará em determinados espaços, ambientes e estruturas sociais. Este autor também remete à formação do habitus todas as experiências vividas durante a vida e durante o processo de formação do sujeito. Com isso, Bourdieu (2009) descreve seu conceito de habitus da seguinte maneira:

História incorporada, feita natureza, e por isso esquecida como tal, o habitus é a presença operante de todo o passado do qual é o produto: no entanto, ele é o que confere às práticas sua independência relativa em relação às determinações exteriores do presente imediato. Essa autonomia é a do passado operado e operante que, funcionando como capital acumulado, produz história a partir da história e garante assim a permanência na mudança que faz o agente individual como mundo no mundo (p. 93, grifo do autor).

Todas as experiências, práticas e influências sociais, educativas e culturais são, em maior ou menor escala, incorporadas pelo sujeito durante a sua trajetória de formação social, cultural, educacional e humana; e estão presentes, sob a forma de capitais incorporados (Bourdieu, 2007) em todas as suas relações e interações sociais, em forma de subjetividade socializada (Bourdieu, 1992 citado por Setton, 2002, p.63).

Não obstante, compreendemos que o habitus é incorporado pelo indivíduo tanto de forma consciente como de forma inconsciente, no entanto, deve-se levar em conta que é importante ter ciência de que as ações de tal sujeito, não necessitam ocorrer, obrigatoriamente, sem que haja reflexão por parte do agente da própria ação. As ações dos sujeitos são consideradas inconscientes devido ao fato de serem reproduzidas de forma natural, porém, em um determinado momento, elas podem se tornar conscientes.

Segundo Setton (2002, p. 63), o conceito de habitus "deve ser visto como um conjunto de esquemas de percepção, apropriação e ação que é experimentado e posto em prática”, o que nos remonta a uma forma de aprendizado social e cultural em um ambiente que é experimentado pelo sujeito, influenciando-o e sendo por ele influenciado. Ainda segundo a autora, "pensar a relação entre indivíduo e sociedade com base na categoria habitus implica afirmar que o individual, o pessoal e o subjetivo são simultaneamente sociais e coletivamente orquestrados" (Setton, 2002, p.63). Assim, podemos vincular ao conceito de habitus todos os esquemas sociais de aprendizado do indivíduo, considerando que o seu passado dialoga com o presente e age na construção de um novo presente.

A reprodução de pensamentos e ações de forma natural se pressupõe como manifestação do capital cultural incorporado pelo indivíduo (Bourdieu, 2007), evidenciando seu habitus constituído. Parte da formação cultural, 
comportamental e ética de uma pessoa ocorre por meio da observação do seu contexto social, através de oportunidades sociais como a família, a escola, a igreja, o trabalho, os amigos e a vizinhança, por exemplo. O acesso a este conjunto de experiências e vivências determina o grau e a qualidade do capital cultural a ser assimilado e incorporado. "O capital cultural é um ter que se tornou ser, uma propriedade que se fez corpo e tornou-se parte integrante da "pessoa", um habitus" (Bourdieu, 2007, p. 7475, grifo do autor).

Segundo Bourdieu e Passeron (2018), o sistema social é estruturado em torno da cultura dominante e tenta reproduzir, predominantemente, a estrutura social vigente, mantendo as relações de poder e os privilégios resultantes destas e, para mantêla, utiliza o próprio sistema social de diversas formas, de modo a resguardar a própria estrutura social de alterações na relação de dominação das classes sociais, mantendo a hierarquia e o domínio pelas mesmas classes nas posições em que se encontram hoje em dia, através de um sistema de reprodução social. Assim, preserva-se o poder e a imposição da cultura de certos grupos em detrimento da cultura de outros. Este sistema se utiliza, dentre outros, do sistema de ensino para homologar a reprodução da estrutura social (Bourdieu \& Passeron, 2018).

Compreendemos, a partir do exposto, que as estruturas sociais constituídas são capazes de determinar e impor práticas sociais e individuais aos sujeitos. Dessa forma, estruturas sociais são construídas, estabelecidas, incorporadas e reproduzidas com o intuito claro e evidente de dominação social. A dinâmica das estruturas sociais dominantes conduz os indivíduos desprestigiados a um sistema de dominação de consciências cujo pensamento predominante é fundado sob o pensamento das classes dominantes. Entretanto, a relação social de dominação existente entre as classes dominantes e as classes dominadas não é revelada de forma tão explícita e direta, como afirma Thiry-Cherques (2006):

[...] a dominação não é efeito direto de uma luta aberta, do tipo "classe dominante" versus "classe dominada", mas o resultado de um conjunto complexo de ações infraconscientes, de cada um dos agentes e cada uma das instituições dominantes sobre todos os demais (p. 50).

Através da compreensão de que "a arte, ela própria, é uma realidade social” (Fischer, 1983, p. 57), é possível alcançar o entendimento que a própria arte poderá estar estigmatizada nestas mesmas estruturas de dominação social, as quais são reproduzidas através de instituições educacionais que propõem o ensino artístico, nas suas mais diversas linguagens, como dança, música, teatro, artes visuais e plásticas, por exemplo.

Um indício dessa reprodução de estruturas de dominação social na maioria das universidades públicas brasileiras, mais especificamente nos cursos de superiores em música, é o processo de seleção de candidatos a esses cursos que emprega os denominados Testes de Habilidades Específicas (THE). Nesse sentido, Sousa \& Monti (2018) desenvolveram uma pesquisa que analisa os THE de cursos de nível superior em música de universidades federais. Segundo estes autores, os testes seletivos “abrangem um conjunto de exames que avaliam certos conhecimentos musicais, como teoria musical, percepção musical, leitura rítmica e solfejo e prática instrumental ou canto" (Sousa \& Monti, 2018, p. 195).

No presente artigo, buscamos a compreensão das condições objetivas e subjetivas no campo educacional dos processos relacionados à utilização do THE nos processos seletivos dos cursos de nível superior em música de universidades públicas brasileiras, observadas as questões fundamentadas por Bourdieu (2007), relacionadas à concepção estruturalista e reprodutivista de estruturas de dominação social através do sistema de educação.

Propomos, outrossim, a discussão acerca dos conteúdos curriculares de cursos superiores de música, na tentativa de se desvelar se seus conteúdos estão partindo de um referencial que remete a um conteúdo de características europeias. Partimos da hipótese de que pode haver no currículo universitário dos cursos de música no Brasil traços que correspondam a um habitus que enfatize características culturais europeias em detrimento de características nacionais, visto que a origem da própria 
universidade é europeia e levando em consideração que "nada mais natural, uma vez que a Europa era o modelo de civilização e cultura da época" (Pereira, 2012, p. 46).

Desta forma, entendemos ser pertinente buscar a compreensão das tensões que emergem das estruturas sociais, bem como de suas relações de dominação, sob o viés do ensino de música, em uma sociedade multicultural, como a sociedade brasileira, no âmbito do ensino superior nacional. Concordamos com Fischer (1983), quando este autor nos apresenta a compreensão de que a dominação social é novamente reproduzida na esfera e no campo do ensino de música e das artes. As expressões artísticas e as obras de arte são utilizadas como artifícios para ocultar, mesmo que em apenas um pequeno espaço de tempo, a divisão aparente de uma sociedade em sujeitos dominantes e dominados, tendo em vista que

[...] numa sociedade dividida pela luta de classes, o efeito "imediato" da obra de arte requerida pela estética dominante é o efeito de suprimir as diferenças sociais existentes na plateia, criando, assim, enquanto a peça vai sendo encenada, uma coletividade "universalmente humana", e não dividida em classes. (Fischer, 1983, p. 15).

A utilização da arte como instrumento de dominação social e de reprodução da cultura das classes dominantes pode se mostrar uma ferramenta consideravelmente intensa e eficaz quando essas reproduções são aplicadas no âmbito do ensino de música nas universidades. O habitus construído, estabelecido e incorporado nas instituições de ensino superior de música no Brasil, surge como uma problematização estudada por autores e pesquisadores na área da Educação, mais especificamente da Educação Musical, os quais buscam compreender os efeitos desta proposta educacional voltada aos moldes europeus.

Um aspecto relevante neste cenário é a aplicação de THE, uma vez que estes podem ser compreendidos na perspectiva de dominação e reprodução socialmente dominante, considerando que

[...] não se pode afirmar apenas pela análise dos THE's (sic) que os cursos analisados são mais ou menos inclusivos, pois não basta este instrumento de avaliação ser multicultural e inclusivo se o restante do curso não for. É necessário, portanto, que diferentes musicalidades, incluindo a erudita, a popular, a folclórica, a midiática e de outras culturas perpassem igualmente diferentes disciplinas, tendo em vista que o nome do curso estudado não é "Licenciatura em Música erudita" ou "Licenciatura em Música popular", mas sim Licenciatura em Música, o que aponta para a totalidade ou pelo menos, uma diversidade de musicalidades. (Sousa \& Monti, 2018, p. 217).

Diante destas questões, buscaremos discutir a influência e a relevância dos THE, e a imposição da tradição musical européia, como conteúdo oficial de ensino em universidades. Traremos à tona, o debate sobre o ensino de música como um instrumento de dominação social, considerando o habitus incorporado pelos sujeitos, como ferramenta de reprodução de estruturas sociais de caráter arbitrário, e a instituição do ensino musical como "produto da interiorização dos princípios de um arbitrário cultural capaz de perpetuar-se" (Bourdieu \& Passeron, 2018, p 53).

\section{Metodologia}

Esta é uma investigação teórica de natureza qualitativa e de cunho sociológico-educacional. Realizamos um estudo bibliográfico com o objetivo de trazer luz às temáticas investigadas e auxiliar a análise dos documentos estudados. As pesquisas desta natureza, de acordo com Bogdan e Biklen (1994), assumem a concepção de que nada é trivial e de que toda informação pode auxiliar o desvendar do objeto investigado.

De acordo com Gil (2009, p. 50) "A pesquisa bibliográfica é desenvolvida a partir de material já elaborado, constituído principalmente de livros e artigos científicos". O referido autor revela ainda que a pesquisa documental possui similitudes com a pesquisa bibliográfica, tendo sua principal diferença na natureza da fonte dos dados, no qual a pesquisa documental se utiliza de materiais, dados e informações brutas, ou seja, que ainda não tenham sido analisadas. (Gil, 2009, p. 51) 
Desta forma, buscando responder as questões desta pesquisa documental, utilizamos algumas técnicas de análise de conteúdo, fundamentada nos escritos de Bardin (2009)

um conjunto de técnicas de análise das comunicações visando obter, por procedimentos, sistemáticos e objetivos(sic) de descrição do conteúdo das mensagens, indicadores (quantitativos ou não) que permitam a inferência de conhecimentos relativos às condições de produção/recepção (variáveis inferidas) destas mensagens. (p.44, grifo do autor)

A utilização dessas técnicas de análise de conteúdo, nos permitem categorizar informações, facilitando o entendimento de questões que não estavam explicitamente reveladas nas palavras.

\section{Habitus e o Ensino de Música na Universidade}

Inquietações a respeito de um habitus que legitima a música europeia como conteúdo primordial são evidenciadas quando Pereira (2012) disserta sobre um habitus hegemônico, o qual é produzido, caracterizado e evidenciado nos currículos dos cursos de música das Instituições de Ensino Superior (IES) brasileiras.

Há diversos autores que discutem as relações de dominação reproduzidas a partir do sistema de ensino nacional. Marques et al (2020, p. 3) posicionam-se a respeito da relação mútua existente entre o habitus e a formação e prática docente do professor de música afirmando que o habitus "ao ser incorporado, promove subjetivações com arrimo nas ditas práticas pedagógicas. Essas vivências são transubstanciadas como resiliência e por ele ressignificadas, como implicações dessas experiências curriculares".

Deste modo, analisar e debater conceitos, fatores e aplicações de elementos presentes em instituições de ensino de música, que sejam responsáveis direta ou indiretamente pela formação pedagógica e musical de professores, notadamente responsáveis pela formação de um habitus característico e, portanto, pela formação de uma cultura específica, se evidencia com bastante relevância para a realização de estudos e pesquisas, especialmente nas IES. Como resultado de pesquisas em torno desta temática, Pereira (2012), em sua tese de doutoramento, apresenta o conceito de habitus conservatorial, o qual é descrito por este autor da seguinte maneira:

[...] compreendemos o conceito de habitus conservatorial como uma descrição típico-ideal das modalidades de valoração musical que organizam as práticas de seleção e distribuição de conhecimento musical. O conceito abrange ainda a concepção de formação de professor de música, baseada nestes esquemas de valoração e organização das práticas, que legitimam a música erudita ocidental e seu valor inerente como conhecimento oficial específico a ser incorporado pelos agentes (p. 135, grifo do autor).

O conceito apresentado explicita a capacidade legitimadora da instituição educacional de nível superior de impor um conteúdo oficial do ensino de música. Neste sentido, o autor visualiza a música erudita ocidental, notadamente a música de origem europeia, com valor de "conhecimento oficial específico a ser incorporado" (Pereira, 2012, p.135) pelos cursos superiores em música no Brasil.

Este conjunto de esquemas de valoração de conteúdos específicos europeus nos currículos dos cursos superiores de música no Brasil, apenas reforça a concepção da tradição europeia ainda enraizada na educação brasileira ou, como menciona Andrade (1977, p. 131), em O Banquete, "nossa tradição é europeia".

Pereira (2012) ainda conceitualiza este esquema de valoração de práticas educacionais na própria formação docente dos estudantes que estão em cursos superiores em música. Este autor identifica que a cultura educacional destes cursos ainda se encontra, mesmo que de forma não-consciente e não totalmente explícita, assentada sob a cultura europeia. Isto posto, compreendemos que tal valoração supera a ideia de herança que se herda, mas produz a condição do herdeiro que é herdado pela própria escola e por seu capital cultural (Bourdieu, 1996). 
Logo, percebemos que a reflexão que aqui iniciamos vai além da existência do próprio habitus ou do habitus conservatorial, mas como esses esquemas comportamentais são instrumentalizados nos currículos dos cursos superiores em música e como um poder simbólico conferido a esses cursos contribui como estratégia capaz de legitimar um conteúdo, construindo uma percepção de conhecimento hegemônico.

Vale salientar que práticas contínuas e repetitivas podem ser caracterizadas como tradicionais e, geralmente, são abertamente aceitas e regidas por regras veladas e não-conscientes, além de possuírem natureza simbólica (Hobsbawn \& Ranger, 2002). A legitimidade posta à tradição conduz à aceitação sem questionamento de certos valores, conhecimentos e práticas pelos condicionamentos impostos, configurando a prática da violência simbólica para o exercício efetivo do poder simbólico (Bourdieu, 2007).

Outro fator necessário de ser mencionado é a condição que as práticas ditas tradicionais e, portanto, mais resistentes às mudanças, podem se estabelecer e se consolidar nos documentos oficiais das instituições de ensino, tornando os sujeitos que as portam ainda mais relutantes a debates, a inovações e a mudanças.

Fato é que a sociedade brasileira descende de diversos povos. Entretanto, fomos condicionados a acreditar que somos sujeitos colonizados e "civilizados" por europeus, logo, é impossível desvincular ou desconsiderar toda uma proposta de ensino construída por séculos, a qual revela através de imposições de valores hegemônicos e que, ao mesmo tempo, se impõe através de mecanismos de violência simbólica.

Entretanto, é importante entendermos os impactos da imposição de uma cultura hegemônica, para buscarmos compreender como o conhecimento musical, voltado para a valoração dos moldes europeus, é manipulado como uma proposta de distinção entre estudantes, ou como o mesmo conhecimento é utilizado com o objetivo de democratizar o acesso ao ensino da música.

Quando refletimos sobre estas contradições, sobre os mecanismos de distinção inerentes ao fazer musical, em contraposição às propostas de ampliação do acesso ao conhecimento musical nos cursos superior em música, percebemos a importância também de discutirmos outro conceito complementar ao habitus que é o capital cultural (Bourdieu, 2007).

\section{O capital Cultural e sua Relação com os Testes de Habilidades Específicas}

O conceito de "capital cultural" de Bourdieu (2007) é apresentado como um sistema de disposições e conhecimentos que poderão ser incorporados, objetivados ou institucionalizados pelos sujeitos, com o objetivo de agregar informações, predisposições e esquemas comportamentais para a sua formação como um indivíduo social e sociável à cultura e ao contexto nos quais estão inseridos.

O capital cultural pode existir sob três formas: no estado incorporado, ou seja, sob a forma de disposições duráveis do organismo; no estado objetivado, sob a forma de bens culturais - quadros, livros, dicionários, instrumentos, máquinas, que constituem indícios ou a realização de teorias ou de críticas dessas teorias, de problemáticas, etc.; e, enfim, no estado institucionalizado, forma de objetivação que é preciso colocar à parte porque, como se observa em relação ao certificado escolar, ela confere ao capital cultural - de que é, supostamente, a garantia - propriedades inteiramente originais (Bourdieu, 2007, p. 74, grifo do autor).

Contextualizando a citação acima com a realidade dos cursos superiores em música no Brasil, e buscando realizar uma reflexão sobre a realidade educacional e o ensino básico através da compreensão da realidade social na qual estamos inseridos, entendemos que as competências e as habilidades dos licenciandos em música não se devem apenas ao seus próprios méritos e desempenho no decorrer da sua formação básica, considerando as três formas de existência do capital cultural. 
Acreditamos na hipótese de haver um conjunto de disposições incorporadas à formação do ser humano, o qual está intrinsecamente relacionado às suas oportunidades de acesso ao conhecimento, alheias ao certificado escolar conferido em sua formação básica, que contribuirão na construção e incorporação de um determinado capital cultural.

Desta forma, esmiuçando e buscando nos aproximar da própria realidade dos cursos superiores em música no Brasil, observamos um fator que, hipoteticamente, segrega o conhecimento musical e os saberes que deveriam ser ofertados de forma democrática, e traduz em estratégias de manutenção das desigualdades sociais, a saber: o THE.

A legitimação e a imposição de um THE para a seleção de estudantes aspirantes a ingressar nos cursos superiores em música no Brasil revela, em parte, uma violência simbólica utilizada sobre os indivíduos desprestigiados socialmente no que diz respeito ao acesso ao campo dos conhecimentos musicais. A falta de oportunidade de lançar mão de tais conhecimentos, determina a sua exclusão do sistema de ensino que deveria fornecer justamente esses conhecimentos exigidos.

Segundo um levantamento, realizado por Sousa \& Monti (2018), no qual estes autores analisam trinta e quatro universidades federais, quatro instituições não aplicam o THE para o ingresso de novos estudantes em cursos superiores em música. Dentre elas, estão a Universidade Federal do Ceará (UFC), Universidade Federal do Cariri (UFCA), Universidade Federal do Pampa (UNIPAMPA) e Universidade Federal de Pelotas (UFPel). Para complementar e atualizar esta lista, verificamos nos estudos de Silva (2019) que mais duas universidades não aplicam o THE: a Universidade Federal de Roraima (UFRR) e a Universidade Federal de Ouro Preto (UFOP).

Com isso, podemos entender que apenas seis universidades federais não aplicam o THE para o ingresso de novos estudantes, e que a maioria das universidades federais brasileiras, utilizam o THE como uma estratégia de seleção para novos estudantes que anseiam em ingressar em um curso superior em música, reafirmando a potencial perspectiva de que os sujeitos aptos a ingressar nesses cursos superiores devem ter em sua própria história, um capital cultural compatível com as exigências impostas pelos organizadores desses processos seletivos.

Ainda segundo Sousa \& Monti (2018, p. 204), a UNIPAMPA e UFPel não aplicam o THE, sob a justificativa que o Sistema Único de Seleção Unificada (SISU) não permite a utilização deste teste para ingresso de novos estudantes, já que a plataforma utiliza a nota do Exame Nacional do Ensino Médio (ENEM) para classificação e seleção de novos estudantes.

Verificamos que a UFRR também utiliza o SISU, omitindo qualquer justificativa burocrática sobre esse procedimento, como processo seletivo em seu Projeto Pedagógico de Curso (PPC).

A UFOP informa o mesmo critério de seleção de novos estudantes no seu PCC (UFOP, 2019), noticiando a decisão através de um comunicado publicado no website da própria universidade:

o curso começou com uma experiência inclusiva e, com essas mudanças, preserva e amplia essa inclusão, uma vez que o processo de musicalização também deve levar em consideração as condições socioeconômicas dos estudantes e o acolhimento, especialmente agora, com o novo processo seletivo. ${ }^{1}$

Em concordância com a UFOP, verificamos que a UNIPAMPA, em seu PPC, afirma que não é coerente exigir um conhecimento musical específico que normalmente não é ensinado na Educação Básica brasileira, conforme podemos verificar:

Pela forma como o licenciando ingressa na UNIPAMPA, através do SiSU e demais formas complementares, dentre elas a de portador de diploma, como acontece com a maioria dos acadêmicos ingressantes no Curso de Música, o

\footnotetext{
${ }^{1}$ Disponível em: <https://ufop.br/noticias/sisu/curso-de-musica-da-ufop-passa-por-transformacoes-para-2019>. Acesso em: 18 de março de 2021.
} 
curso de Licenciatura em Música não prevê prova de habilitação específica em fundamentos teóricos e práticos da música. Embora tenhamos a Lei federal 11.769/08, que prevê o conteúdo música como obrigatório na educação básica, ainda não existe estudo de música sistematizado no referido nível de ensino. No entendimento do Curso de Música, uma prova de habilitação específica não contempla a diversidade cultural de formação musical dos licenciandos que ingressam, correndo-se o risco de avaliarmos apenas uma determinada manifestação musical em detrimento de outras. (Universidade Federal do Pampa, 2014, p. 36).

Com isso, podemos compreender que não é apenas o argumento burocrático alusivo ao SISU que justifica a não utilização do THE como processo seletivo na UNIPAMPA, mas uma reflexão mais ampla sobre não existir um estudo de música sistematizado na escola.

Podemos destacar que, durante um período, a Lei de Diretrizes e Bases da Educação Nacional (LDB) previu a obrigatoriedade do ensino de música no componente curricular de "Ensino de Arte" da educação básica, até que a Lei 13.278, de 02 de maio de 2016, ampliou esse entendimento e, a fim de contemplar as outras linguagens artísticas, incluiu "as artes visuais, a dança, a música e o teatro" no componente curricular citado (Brasil, 2016).

Ainda com o objetivo de buscar compreender as funções e impactos sobre tais processos de seleção, utilizaremos o recorte de um estudo acadêmico publicado pela Universidade Federal de Uberlândia, que afirma

Para o processo seletivo de Certificação de Habilidade Específica (obrigatória no concurso vestibular) o manual do candidato apresenta algumas diretrizes para a prova de leitura musical e testes auditivos. São atribuídos quarenta pontos distribuídos em cinco questões que abordam dois aspectos distintos: melódico e rítmico. No aspecto melódico observa-se o contorno melódico, senso tonal, relação intervalar, afinação, precisão rítmica e fluência. Já no aspecto rítmico a ênfase se dá na pulsação métrica, conhecimento da célula rítmica a ser reproduzida e fluência. Indo ao encontro dos aspectos solicitados são apresentados os conteúdos programáticos que englobam as leituras rítmicas, os solfejos melódicos, os intervalos, os acordes, a afinação e a memória. (Gouveia, 2014, p. 417)

Uma observação pertinente a se realizar é que os fundamentos e práticas musicais exigidas nos Testes de Habilidades Específicas não são condizentes com a realidade do ensino de música na educação básica brasileira. Logo, a necessidade de um conhecimento prévio de conteúdos de matrizes europeias é um marco essencial no capital cultural dos estudantes, para que possam ter uma formação superior em música em uma universidade pública brasileira.

Desta forma, diante do exposto, percebemos que existe um dilema: ao considerarmos que a universidade pública possui a missão social da democratização do conhecimento, se torna incoerente a utilização de mecanismos de seleção que exijam conhecimentos não tão acessíveis, como o próprio conhecimento musical na educação básica.

Com isso, observamos como essas heranças simbólicas do ensino acadêmico de música, influenciadas e reprodutoras de um habitus que impõe um conteúdo hegemônico como oficial, podem surgir com um impasse para a difusão do conhecimento universal, público, gratuito e de qualidade.

Em concordância com a UNIPAMPA, e em discordância com o que é defendido pela UFPel em seu sítio eletrônico ${ }^{2}$ apresentamos a realidade da Universidade Federal do Ceará (UFC), que segundo Sousa \& Monti (2018):

apesar de ter aderido ao SISU, não o apresentou como motivo da instituição não aplicar o THE, mas sim pelo fato das desigualdades sociais impedirem que diferentes pessoas tenham condições fatídicas de estudar Música, e que tais aspectos não poderiam ser medidos por meio de um THE (Sousa \& Monti, 2018, p. 206)

\footnotetext{
2 “Apesar de atualmente o MEC não permitir que seja feito teste de habilitação junto ao ingresso pelo SISU, é importante que o candidato interessado em cursar algum dos Bacharelados em Música ofertados pelo Centro de Artes da UFPel saiba que é necessário ter conhecimento prévio de teoria musical e possuir proficiência em seu instrumento de escolha." Disponível em: 〈https://wp.ufpel.edu.br/musica/ingresso/>. Acesso em: 03 de fevereiro de 2021.
} 
Na UFC, o processo seletivo de novos estudantes, não exige um THE, ofertando vagas para um curso superior em música, em uma universidade pública, com a proposta de ampliar o acesso ao conhecimento musical, sem impor exigências de fundamentações e práticas musicais, sejam de matriz européia ou não, para o ingresso de novos estudantes ao seu corpo discente.

A opção desse PPC por manter a não realização de um Teste de Habilidade Específica - THE, como já ocorria na primeira proposta curricular do curso, datada de 2005, como requisito de ingresso, constitui-se não apenas em uma forma de democratizar o acesso ao ensino de Música, em nível superior, em uma cidade como Fortaleza que não possui escola pública e gratuita de Música de nível básico. Trata-se também de uma estratégia pedagógica, a partir da qual a heterogeneidade de níveis de conhecimento dos estudantes em uma mesma turma servirá de laboratório para discussões, desde os primeiros dias de aula, acerca de possíveis abordagens didáticas para a Educação Musical, valorizando a colaboração e a aprendizagem musical compartilhada nas diversas disciplinas. (Universidade Federal do Ceará, 2015, p. 22)

A proposta curricular no curso de licenciatura em música da Universidade Federal do Ceará não ignora o capital cultural dos seus estudantes, mas tenta compreender a heterogeneidade dos capitais culturais dos alunos, além de buscar não restringir o acesso dos candidatos à universidade.

Faz-se importante ressaltar que a não-obrigatoriedade de um THE na UFC antecede o SISU, sendo parte significativa de sua história de institucionalização do curso de música em questão, e que foi registrado em seu primeiro PPC (Universidade Federal do Ceará, 2005).

Os alunos candidatos ao curso serão selecionados através, do processo regular, concurso vestibular, sem a necessidade de realização de teste de aptidão musical. Buscamos, desta forma, criar oportunidades de estudo da música sem cobrar dos candidatos um conhecimento que ainda não é acessível a todas as pessoas, evitando a criação de empecilhos desnecessários. (Universidade Federal do Ceará, 2005)

\section{Resultado e Discussão}

É possível deduzir, a partir da leitura desta reflexão teórica, quando nos deparamos com os princípios de uma teoria de educação reprodutiva, descrita e defendia por Pierre Bourdieu, com o diálogo de outros pesquisadores, a necessidade de nos debruçarmos para analisar essas questões sociais que vão além dos próprios muros das escolas e universidades.

A compreensão social dos sujeitos e as oportunidades de acesso ao conhecimento, seja ele musical ou não, são e serão fatores determinantes para estudantes que manifestem o interesse em ingressar em um curso superior em música no Brasil. Diante disso, torna-se necessário refletirmos sobre os processos seletivos de ingresso dos pretendentes a uma vaga em cursos de música em universidades públicas, para que as IES públicas no Brasil possam reformular as suas prioridades de maneira a realmente cumprir a sua função social e pedagógica.

Logo, os testes avaliativos para o ingresso de estudantes nas graduações em música em universidades federais, podem se revelar como ferramentas excludentes de classes menos favorecidas. Quando refletimos sobre uma educação democrática, percebemos ainda mais a necessidade de adequação do sistema de ensino superior, especialmente nos cursos de música, à democratização do acesso a todos de forma indistinta e justa.

\section{Considerações Finais}

Os corpos docentes dos cursos superiores em música necessitam refletir urgentemente sobre as questões abordadas nesse artigo, a fim de que a própria universidade se torne mais acessível e democrática. Desconstruindo o estigma de um conhecimento musical hegemônico, voltado exclusivamente à moldes da música de matriz europeia. 
Entretanto, não é possível afirmar que a não utilização de THE torne os cursos superiores em música mais acessíveis. Embora algumas universidades não utilizem os THE em seu processo seletivo, nosso estudo não aprofundou a análise dos documentos e canais oficiais, afim de comprovar a necessidade de conhecimentos prévios no decorrer da formação superior do estudante.

Com isso, consideramos ser necessário refletir não apenas sobre o processo seletivo em questão, mas em um conjunto de disposições que estão inconscientemente incorporadas nos currículos dos cursos de superior em música no Brasil, bem como evidenciam os estudos de Pereira (2012), Silva (2019), dentre outros.

\section{Referências}

Andrade, M. (1977) O banquete. Duas Cidades.

Bardin, L. (2009) Análise de conteúdo. Edições 70.

Bogdan, R. C., Biklen, S. K. (1994). Investigação qualitativa em educação: uma introdução à teoria e aos métodos (M. J. Alvarez, S. B. dos Santos, T. M. Baptista, Trad.). Porto Editora (Obra Original publicada em 1991).

Bourdieu, P., Passeron, J-C. (2018). A reprodução: elementos para uma teoria do sistema de ensino. Editora Vozes.

Bourdieu, P. (2007). Escritos de educação. M. A. Nogueira, A. Catani (Orgs). Editora Vozes.

Bourdieu, P. (1996). As regras da arte (M. L. Machado, Trad.). Companhia das Letras (Obra Original publicada em 1992).

Bourdieu, P. (2009). O senso prático (M. Ferreira, Trad.). Editora Vozes (Obra Original publicada em 1980).

Brasil. (2016). Lei 13.278, de 02 de maio de 2016. Altera o $§ 6^{\circ}$ do art. 26 da Lei $\mathrm{n}^{\circ} 9.394$, de 20 de dezembro de 1996 , que fixa as diretrizes e bases da educação nacional, referente ao ensino da arte. Brasília, DF. http://www.planalto.gov.br/ccivil_03/_ato2015-2018/2016/lei/113278.htm.

Brasil (1996). Lei 9.394, de 20 de dezembro de 1996. Estabelece as diretrizes e bases da educação nacional. Brasília, DF. http://www.planalto.gov.br/ccivil_03/leis/19394.htm.

Fischer, E. (1983). A necessidade da arte (9th ed.). Zahar Editores.

Gil, A. C. (2009). Métodos e técnicas de pesquisa social (6 ${ }^{\mathrm{a}}$ Ed.). Atlas.

Gouveia, R. A. (2014). Certificação de habilidade específica: leitura musical, testes auditivos e conceitos de avaliação. Anais do III SIMPOM (nº 3). Rio de Janeiro, RJ: Unirio. http://www.seer.unirio.br/index.php/simpom/article/view/4576.

Hobsbawan, E. J., Ranger, T. O. (2002). A invenção das tradições (3rd ed.). Paz e Terra.

Kaczan, M., Rogério, P., Kaczan, M. A. V. L. (2020). Experiências educativo-musicais na formação de um habitus musical. Revista Roteiro (UNOESC), volume 45, 1-16. https://doi.org/10.18593/r.v45i.23787

Pereira, M. V. M. (2012). Ensino Superior e as Licenciaturas em Música: um retrato do habitus conservatorial nos documentos curriculares. Tese de Doutorado, Universidade Federal do Mato Grosso do Sul, Campo Grande, Mato Grosso do Sul, Brasil.

Setton, M. da G. J. (2002). A teoria do habitus em Pierre Bourdieu: uma leitura contemporânea. Revista Brasileira de Educação (nº 20 ), 60-70.

Silva, E. T. da. (2019). Testes de aptidão musical em cursos de licenciatura em música: desnaturalização do conceito e suas implicações em ações educativomusicais. Tese de Doutorado, Universidade Federal do Ceará, Fortaleza, Ceará, Brasil.

Sousa, R. S. de., Monti, E. M. do. (2018). Qual é o perfil de quem pode entrar? Uma análise dos testes de habilidades específicas de cursos de licenciatura em música de universidades federais. Revista trimestral do Grupo de Pesquisa Educação, Artes e Inclusão (GPEAI/UDESC), volume 14 (nº 4), 194-220. http://dx.doi.org/10.5965/1984317814042018194

Thiry-Cherques, H. R. (2006). Pierre Bourdieu: a teoria na prática. Revista de Administração Pública, volume 40 (nº 1$), 27-53$.

Universidade Federal do Pampa (2016). Projeto Pedagógico do Curso De Licenciatura Em Música. http://cursos.unipampa.edu.br/cursos/licenciaturaemmusica/files/2019/01/ppc-2017-com-ementario_atualizacao-jan_2019.pdf.

Universidade Federal do Ceará. (2005). Projeto Pedagógico de Curso: graduação em pedagogia, educação musical e educação física da faculdade de educação. A. M. I. Dias, M. De L. P. Brandão, C. M. Braga, Y. K. O. Rodrigues (Orgs.). UFC/Pró-Reitoria de Graduação.

Universidade Federal do Ceará. (2015). Projeto Pedagógico do Curso de Licenciatura em Música. 
Research, Society and Development, v. 10, n. 5, e0510514570, 2021

(CC BY 4.0) | ISSN 2525-3409 | DOI: http://dx.doi.org/10.33448/rsd-v10i5.14570

Universidade Federal de Ouro Preto. (2019). Projeto Pedagógico do Curso de Licenciatura em Música. https://musica.ufop.br/sites/default/files/musica/ files/projeto_pedagogico_musica_2.pdf?m=1567582617. 